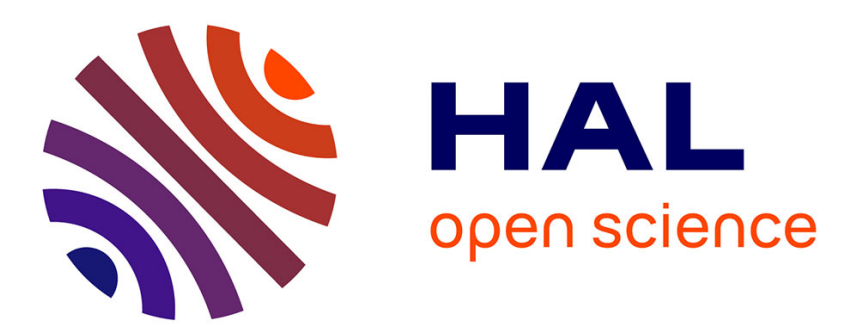

\title{
Ab Initio Prediction of the Redox Potentials of 3d Transition Metals Embedded in a Semiconducting Host Lattice
}

William Lafargue-Dit-Hauret, Camille Latouche, Stéphane Jobic

\section{- To cite this version:}

William Lafargue-Dit-Hauret, Camille Latouche, Stéphane Jobic. Ab Initio Prediction of the Redox Potentials of 3d Transition Metals Embedded in a Semiconducting Host Lattice. Journal of Physical Chemistry C, 2021, 125 (7), pp.4267-4276. 10.1021/acs.jpcc.0c11203 . hal-03194209

\author{
HAL Id: hal-03194209 \\ https://hal.science/hal-03194209
}

Submitted on 9 Apr 2021

HAL is a multi-disciplinary open access archive for the deposit and dissemination of scientific research documents, whether they are published or not. The documents may come from teaching and research institutions in France or abroad, or from public or private research centers.
L'archive ouverte pluridisciplinaire HAL, est destinée au dépôt et à la diffusion de documents scientifiques de niveau recherche, publiés ou non, émanant des établissements d'enseignement et de recherche français ou étrangers, des laboratoires publics ou privés. 


\title{
$A b$ initio prediction of the redox potentials of $3 d$ transition metals embedded in a semiconducting host lattice
}

\author{
William Lafargue-Dit-Hauret, Camille Latouche, Stéphane Jobic* \\ Université de Nantes, CNRS, Institut des Matériaux Jean Rouxel, IMN, F-44000, Nantes, France
}

Here, we report a theoretical investigation devoted to the ab initio determination of the redox potentials $E\left(D^{n+} / D^{n+1}\right)$ of a dopant $D$ in a given host lattice. The knowledge of these potentials is of capital importance to anticipate its attainable oxidation states (versus the synthesis conditions). Hereafter the host lattice has been selected to be the well-known rutile $\mathrm{TiO}_{2}$ compound due to its interest for many applications, the simplicity of its crystal structure and the large number of already collected data. Dopants are $3 \mathrm{~d}$ transition metals (i.e., V, Mn, Fe, $\mathrm{Ni}$ and $\mathrm{Cu}$ ) substituting titanium atoms. First-principles methods combined to the SCAN functional were used to determine the electronic properties of doped materials considering the supercell approach. The stability of point defects (intrinsic and extrinsic) at different charge states are discussed based on the estimation of their defect formation enthalpies, and the associated charge transition levels are calculated and positioned in the gap of the un-doped material.

\section{Introduction}

Physical properties of a semiconducting phase can be significantly improved via the control of its intrinsic defects. Hence, the existence of donor (acceptor) levels has to be privileged at the expense of acceptor (donor) ones to favor n-typeness (p-typeness). Substitutions can also play a major role in engineering the performances of a material or to develop new functionalities. In that framework, the question to be addressed therefore concerns the dopability of the material and the achievable oxidation states of the dopant (also called impurity in the following) in our host lattice. Hereafter, we assess the ability of DFT calculations to predict the stability of a $3 \mathrm{~d}$ transition metal (namely, V, Mn, Fe, Ni and Cu hereafter generically named TM) used as dopant in the well-known $\mathrm{TiO}_{2}$ rutile compound. 
Beyond the fact that $\mathrm{TiO}_{2}$ is environmentally friendly, this compound presents other advantages such as a high chemical stability and a low cost which strongly encourage its incorporation into daily life objects. Regarding the electronic properties, this wide band gap material belongs to the transparent semiconducting oxide's family. Point defects have already been widely investigated for the rutile $\mathrm{TiO}_{2}$ phase through experimental and theoretical studies, ${ }^{1-15}$ even if some conflicting points are still a matter of debate within the community such as the exact nature of the dominant defect or the depth of donor levels for oxygen vacancies.

So far, great efforts have been devoted to take benefit of the natural properties of $\mathrm{TiO}_{2}$ and to enlarge its applications spectrum. Notably, $\mathrm{TiO}_{2}$ has been used as an host matrix for chemical doping. These intentionally introduced point defects are well-known to create local structural distortions and in-gap electronic states, ${ }^{16-20}$ which may significantly modify the electronic, magnetic and/or optical properties of host materials. In the case of the $\mathrm{TiO}_{2}$ compound, the introduction of transition metal (TM) dopants has been reported to enhance photocatalytic, ${ }^{21-29}$ electrocatalytic ${ }^{30,31}$ or ferromagnetic ${ }^{32-41}$ properties, but also to alter the irreversible anatase-torutile phase transition. ${ }^{42}$

It remains evident that properties strongly depend on the electronic configuration of impurities, which is usually discussed through their oxidation state. If the targeted properties (magnetism for instance) are directly related to the electronic configuration of TM, the knowledge of the stability domain of a dopant species in a given charged state is capital. It is thus crucial to determine the redox stability domain of a dopant embedded in a given host lattice versus its charge state. In some aspects, one can make a parallel with the $\mathrm{pKa}$ of an acid/base couple that provides information on the acid (base) and conjugate base (acid) species concentrations in solution at a given $\mathrm{pH}$. Determination of the redox potential $\mathrm{E}\left(\mathrm{D}^{\mathrm{n}+} / \mathrm{D}^{\mathrm{n}+1}\right)$ associated to a transition frontier (or level) between a dopant $D$ with the charge states $n+$ and $n+1$ opens up the door to anticipate the observed oxidation state of the dopant for a given external potential, or more commonly, a given electronic potential $\mu_{E_{F}}$. More specifically, this potential corresponds to the electrons' electrochemical potential at which the oxidized and reduced species coexist in identical concentrations. When the measured potential leaves the equilibrium point, the expected population of each species drastically evolves according to a Boltzmann distribution. Hereafter, the electronic potential $\mu_{E_{F}}$ value at which the concentrations of two charge states $q$ and $q^{\prime}$ of the same point 
defect are equilibrated is called transition level $\epsilon\left(q / q^{\prime}\right)$ (with $q^{\prime}$ possibly different from $q+1$ or $q-1)$. The knowledge of these points is of particular interest for experimentalists who would be able to orientate syntheses to favor specific charge states of defects in a given host structure to achieve the desired properties.

Mizushima et al. $^{43-45}$ firstly reported combined experimental and theoretical systematic investigation of transition levels for $\mathrm{TM}$ impurities in rutile $\mathrm{TiO}_{2}$. Experimentally, oxygen content in synthesis atmosphere and lithium interstitials have been used to tune the position of $\mu_{E_{F}}$ and approach the stability domains of charged defects. By the use of a semi-empirical procedure ${ }^{46}$, transition level positions were estimated for different oxidation states of several TMs. These studies have been completed by photocurrent and ESR measurements few years later ${ }^{47}$. Surprisingly, to our knowledge, only few other experimental studies have been reported on systematic characterization of TM doping in this material. ${ }^{48-52}$ In parallel, plenty of first-principles insights have been collected on doped rutile $\mathrm{TiO}_{2}$. Formation energies and charge transition levels of

intrinsic defects have been carefully detailed through the use of density functional theory. ${ }^{7-11,53,15}$ However, authors often did not consider extrinsic dopants. Regarding the impurities, most of articles report energy level positions determined through the analysis of densities of states. ${ }^{13,54-56}$ If few studies have been devoted to the determination of the formation energies associated to the substitution of TM dopants for $\mathrm{Ti}$, different approaches have been used which make their comparison delicate. Herein, we propose to fill this lake by investigating intrinsic defects but also substituting elements as vanadium, manganese, iron, nickel and copper at Ti site. Also, we take benefit of this study to explore defects properties with the fashionable meta-GGA SCAN functional. ${ }^{57}$ If the energy levels of oxygen vacancies have already been studied through densities of states, ${ }^{58}$ defect formation energies or charge transition levels have never been reported before.

\section{Methods}

\section{Point defects notation}

In the current paper, point defects are represented by the $A_{X}^{c}$ notation where $A$ refers to the substituting species ( $V$ in case of vacancy), $X$ to the substituted element in the ideal structure ( $i$ in 
case of an empty interstitial site) and $c$ the relative charge state compared to the regular charge of $X$. To avoid any confusion between vacancy and vanadium, the chemical symbol of the vanadium element $V$ will be arbitrarily written $V a$ except when the context precludes any ambiguity.

\section{$a b$ initio calculations}

We performed first-principles calculations using the Density Functional Theory (DFT) within the projector augmented wave (PAW) approach, as implemented within the VASP software. ${ }^{59-61}$ In this study, the expansion of the plane wave basis set is fixed by a cutoff energy of $500 \mathrm{eV}$, and the meta-GGA $\mathrm{SCAN}^{57}$ exchange-correlation functional was used. Full geometry relaxations were performed on the rutile $\mathrm{TiO}_{2}$ unitcell until forces are less than $0.01 \mathrm{eV} / \AA .7 \times 7 \times 11$ and $9 \times 9 \times 13 \Gamma$-centered $k$-points meshes were considered to sample the first Brillouin zone for the geometry relaxations and accurate energy calculations on the unit cell, respectively. A more accurate band gap was determined using the screened hybrid functional HSE06 ${ }^{62}$ on top of the fully relaxed SCAN structure.

For the sake of comparison, we also performed a full geometry relaxation and band gap calculation with other approaches such as PBE, ${ }^{63} \mathrm{PBE}+\mathrm{U}$ with $U_{\text {eff }}=4.2 \mathrm{eV},{ }^{9} \mathrm{PBEsol}^{64}$ and HSE06. ${ }^{62}$ Table 2 in SI summarizes the lattice parameters, electronic band gaps and interatomic distances determined with different exchange-correlation functionals. In terms of lattice parameters, a great agreement is obtained using the SCAN or HSE06 functionals with respect to experimental data, while the three other functionals tend to overestimate these values within the PBE error range ( $\sim 2 \%)$. For the SCAN functional, $a$ and $c$ values of $4.596 \AA$ and $2.968 \AA$ are very close to experimental data issued from powder neutron diffraction data $(a=4.59308(4) \AA$ and $c=$ $2.95889(3) \AA) .{ }^{65}$ In the following, all calculations are carried out with the SCAN functional. HSE06@SCAN calculations were used to get a corrected value of the bandgap which is required to accurately study the material's defects.

Defect formation enthalpies (DFEs) were calculated within the supercell approach. A $2 \times 2 \times 4$ supercell containing 96 atoms was constructed. Atomic positions were relaxed in faulted structures until forces acting on ions are less than $0.02 \mathrm{eV} / \AA$. We performed the structural optimizations and accurate energy calculations using $4 \times 4 \times 3$ and $5 \times 5 \times 4 \Gamma$-centered $k$-points meshes, respectively. 
The supercell is supposed to be large enough that the insertion of a point defect does not induce (or marginally) any change in the cell volume. In such a situation, DFEs were calculated considering the following formula:

$$
\Delta_{f} H^{D, q}\left(\mu_{E_{F}}\right)=E_{\text {tot }}^{D, q}-E_{\text {tot }}^{\text {host }}+\sum_{i} n_{i} \mu_{i}+q\left(E_{V B M}^{\text {host }}+\mu_{E_{F}}\right)+E_{c o r r}(D, q)
$$

where $\Delta_{f} H^{D, q}$ is the formation enthalpy of a defect $D$ in a state of charge $q, E_{\text {tot }}^{D, q}$ is the total energy of the faulted supercell, $E_{\text {tot }}^{\text {host }}$ is the total energy of the host supercell, $n_{i}$ is the number of atoms of the $i^{\text {th }}$ species added $\left(n_{i}<0\right)$ or removed $\left(n_{i}>0\right)$ from the ideal probed material, $\mu_{i}$ is the chemical potential of the $i^{\text {th }}$ specie, $\mu_{E_{F}}$ is the chemical potential of the electron reservoir and $E_{V B M}^{\text {host }}$ is the energy corresponding to the valence band maximum (VBM) of the host which fixes the $\mu_{E_{F}}$ reference. $E_{c o r r}$ corresponds to various corrections of spurious effects, such as electrostatic interactions between point defects or the potential alignment allowing to retrieve the electronic reference of the host material. More details on this term are provided in SI.

The chemical potential $\mu_{i}$ corresponds to the atomic reservoir of the $i^{\text {th }}$ atomic specie during the crystal growth. Obviously, this quantity strongly depends on the synthesis conditions and drives the thermodynamic stability between the different competitive phases. For a given $i^{\text {th }}$ atomic species, the chemical potential $\mu_{i}$ may be decomposed as the sum of the standard chemical potential $\mu_{i}^{0}$ and the deviation $\Delta \mu_{i}$ which depends on synthesis conditions.

The charge transition level $\epsilon\left(q / q^{\prime}\right)$ between two charge states $q$ and $q^{\prime}$ corresponds to the $\mu_{E_{F}}$ level at which their respective DFEs are equivalents, i.e., the populations of both $q$ and $q^{\prime}$ states are identical within the material for this specific potential. Such thermodynamic quantity is expressed as:

$$
\epsilon\left(q / q^{\prime}\right)=\frac{\Delta_{f} H^{D, q}\left(\mu_{E_{F}}=0\right)-\Delta_{f} H^{D, q^{\prime}}\left(\mu_{E_{F}}=0\right)}{q^{\prime}-q}
$$

where $\Delta_{f} H^{D, q}$ and $\Delta_{f} H^{D, q^{\prime}}$ are the formation enthalpies of a defect $D$ in the charged states $q$ and $q^{\prime}$, respectively. 
Assuming all defects are formed during the synthesis process at a given temperature $\left(T_{\mathrm{gr}}\right)$ and their concentration maintained after quenching of the structure to room temperature, the concentration $n_{D, q}\left(E_{F}\right)$ of a defect $D$ in a charge state $q$ can be determined for a given Fermi level $E_{F}$ (i.e., a given temperature $T$ since $E_{F}$ depends on $T$ ) through a Fermi-Dirac distribution commonly approximated by a Boltzmann one of the $N$ available sites per volume unit:

$$
n_{D, q}\left(E_{F}\right)=N \cdot \exp \left(-\frac{\Delta_{f} H^{D, q}\left(E_{F}\right)}{k_{B} T}\right)
$$

In that context, the Fermi level is determined by solving iteratively the charge neutrality equation:

$$
-n_{e}\left(E_{F}\right)+n_{h}\left(E_{F}\right)+\sum_{D} \sum_{q_{i} \in q_{D}} q_{i} \cdot n_{D, q_{i}}\left(E_{F}\right)=0
$$

with $n_{e}\left(E_{F}\right)$ and $n_{h}\left(E_{F}\right)$ the concentrations of free electrons in the conduction band and holes in the valence band at $T$, respectively. Such quantities are determined through:

$$
n_{e}\left(E_{F}\right)=\int_{E_{C}}^{+\infty} g_{e}(E) f_{F D}\left(E-E_{F}\right) d E
$$

and

$$
n_{h}\left(E_{F}\right)=\int_{-\infty}^{E_{V}} g_{h}(E)\left(1-f_{D F}\left(E-E_{F}\right)\right) d E
$$

where $f_{F D}\left(E-E_{F}\right)$ corresponds to the Fermi-Dirac function:

$$
f_{F D}\left(E-E_{F}\right)=\frac{1}{1+\exp \left(\frac{E-E_{F}}{k_{B} T}\right)}
$$

and $g_{e}(E)$ and $g_{h}(E)$ are the 3D density of states of electrons and holes, respectively:

$$
g_{e, h}(E)=\frac{1}{4 \pi^{2}}\left(\frac{2 m_{e, h}^{*}}{\hbar^{2}}\right)^{\frac{3}{2}} \sqrt{E}
$$


where $m_{e}^{*}$ and $m_{h}^{*}$ are associated to the electron and hole effective masses, respectively. Experimentally, the reported electron effective mass values are highly disparate, ranging from about $3,{ }^{66} 10^{64}$ to $25-30,{ }^{2,68}$ according to the authors. Herein, these quantities were determined from the parabolic curve fitting of the conduction band minimum (CBM) and valence band maximum (VBM). We estimated $\mathrm{m}_{\mathrm{e}} * / \mathrm{m}_{0}$ and $\mathrm{m}_{\mathrm{h}} * / \mathrm{m}_{0}$ values at 0.68 and 2.72 . Our results appear slightly larger than those obtained at the PBE level by Zhang et al. ${ }^{69}\left(m_{e}^{*} / m_{0}=0.10\right.$ and $\left.m_{h}^{*} / m_{0}=0.56\right)$.

All defect post-treatments presented above were performed using the PyDEF 2.0 software. $^{70,71}$

\section{Results and discussions}

The $\mathrm{TiO}_{2}$ rutile phase crystallizes in the tetragonal space group $P 4_{2} / \mathrm{mnm}^{65}$ with two formula units per unit cell and only two distinguishable atoms, titanium and oxygen, located at $2 a$ and $4 f$ Wyckoff positions, respectively. The electronic band gap of $2.12 \mathrm{eV}$ obtained within the SCAN approach appears underestimated compared to the experiment (3.05-3.1 $\mathrm{eV}^{1,72}$ or $3.3 \mathrm{eV}^{73}$ ) or the HSE06 functional $(3.36 \mathrm{eV})$. A more accurate electronic band gap of $3.30 \mathrm{eV}$ was obtained based on HSE06 calculations on optimized SCAN structures (HSE06@SCAN). This procedure was used for the band-edges correction of faulted supercells during the estimation of DFEs (and the determination of the $\epsilon\left(q / q^{\prime}\right)$ transition level positions).

Before investigating substitution of $\mathrm{Ti}$ atoms by $\mathrm{TM}$ species, the knowledge of the dopability domain delimited by intrinsic species is necessary. This domain is inspected here under O-poor and O-rich atmospheres.

\section{Intrinsic point defects}

\section{Chemical potentials}

Rutile $\mathrm{TiO}_{2}$ naturally exhibits an intrinsic $n$-type conductivity ${ }^{4,6,74}$ with a mobility of the charge carriers that can reach half of crystalline silicon values. ${ }^{6}$ Surprisingly, the nature of the dominant defect is still controversial. So far, oxygen vacancies $V_{O}$ and titanium interstitials $T i_{i}$ have been pointed out to be responsible for by many theoretical and experimental studies. ${ }^{7-}$ 9,14,15,53,75 Nevertheless, these electron donor defects, if associated to defects energy levels located in the conduction band (see below), may also retrocede electrons to the host lattice that would be preferentially localized in the direct neighboring of $\mathrm{Ti}^{4+}$ sites creating $\mathrm{Ti}^{3+}$ species and small 
polarons. ${ }^{12,76-79}$ Moreover, conclusions from theoretical predictions on the depth of $V_{O}$ defects are sometimes conflicting between shallow and deep nature. $7,9,11,14,15,74,80$

In that context, the thermodynamic stability of rutile $\mathrm{TiO}_{2}$ synthesized under different atmospheres was reinvestigated. To do so, 10 competitive phases (i.e., Ti, $\mathrm{O}_{2}, \mathrm{Ti}_{6} \mathrm{O}, \mathrm{Ti}_{3} \mathrm{O}, \mathrm{Ti}_{2} \mathrm{O}$, $\mathrm{TiO}, \mathrm{Ti}_{2} \mathrm{O}_{3}, \mathrm{Ti}_{3} \mathrm{O}_{5}, \mathrm{Ti}_{4} \mathrm{O}_{7}$ and $\mathrm{Ti}_{5} \mathrm{O}_{9}$ ) were considered in relation with the experimental Ti-O phase diagram, ${ }^{81}$ while previous reported DFT studies took into account only 3 (i.e., Ti, $\mathrm{O}_{2}$ and $\left.\mathrm{Ti}_{2} \mathrm{O}_{3}\right)^{7,9,15}$ The hcp- $\mathrm{Ti}_{(\mathrm{s})}$ and $\mathrm{O}_{2(\mathrm{~g})}$ phases were used to set the chemical potential references $\mu_{T i}^{0}$ and $\mu_{O}^{0}$, respectively. We emphasize the fact that the actual study only focuses on the rutile $\mathrm{TiO}_{2}$ phase and neglects the competition with other stable (i.e., brookite and anatase) and metastable (i.e., columbite, ramsdellite, bronze, hollandite) phases of titania.

Figure 1 displays the stability domain for the rutile $\mathrm{TiO}_{2}$ compound within the theoretical Ti-O phase diagram. Clearly, the chemical potential limits of $\mathrm{O}$ and $\mathrm{Ti}$ are delimitated by $\mathrm{O}_{2}$ gas and $\mathrm{Ti}_{5} \mathrm{O}_{9}$ solid phases. For $\mathrm{O}$-rich/Ti-poor synthesis conditions, $\mu_{T i}$ and $\mu_{O}$ are respectively set to -26.43 and -6.02 eV $\left(\Delta \mu_{T i}=-10.45 \mathrm{eV}\right.$ and $\left.\Delta \mu_{O}=0.00 \mathrm{eV}\right)$. For O-poor/Ti-rich conditions, $\mu_{T i}$ and $\mu_{O}$ are equal to -18.17 and $-10.15 \mathrm{eV}\left(\Delta \mu_{T i}=-2.19 \mathrm{eV}\right.$ and $\left.\Delta \mu_{O}=-4.13 \mathrm{eV}\right)$.

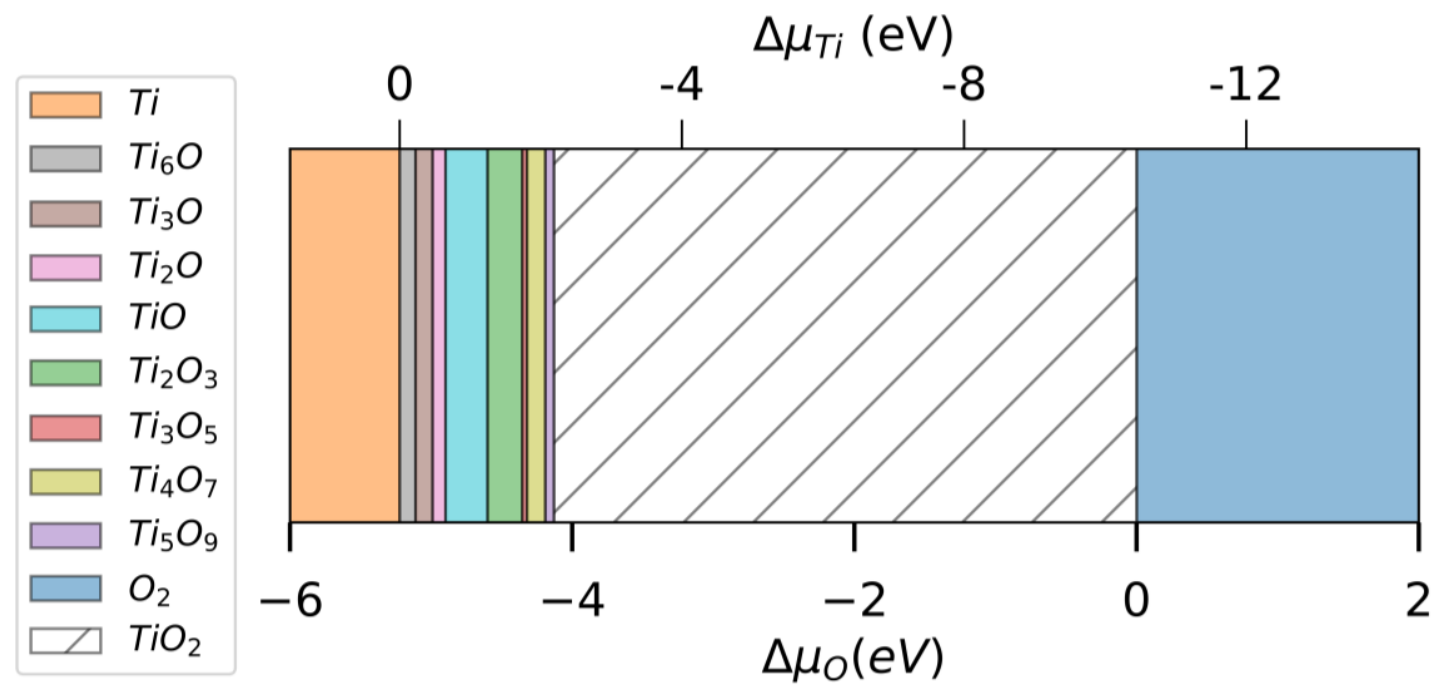

Figure 1 Stability domain of $\mathrm{TiO}_{2}$ as a function of the chemical potential deviations. In oxidized (O-rich) conditions, $\Delta \mu_{O}=0 \mathrm{eV}$ and $\Delta \mu_{T i}=-10.45 \mathrm{eV}$, as the formation enthalpy $\Delta_{f} \mathrm{H}$ of $\mathrm{TiO}_{2}$ $\left(\Delta_{f} \mathrm{H}\left(\mathrm{TiO}_{2}\right)=\Delta \mu_{T i}+2 \Delta \mu_{O}\right)$ is found to be $-10.45 \mathrm{eV}$ (very close to the experimental value of $-9.78 \mathrm{eV}) .^{82}$ Under reduced (O-poor) atmospheres, the $\mathrm{Ti}_{5} \mathrm{O}_{9}$ phase bounds the stability domain of $\mathrm{TiO}_{2}$ at $\Delta \mu_{O}=-4.13 \mathrm{eV}$ and $\Delta \mu_{T i}=-2.19 \mathrm{eV}$. 


\section{Defect formation enthalpies and defect concentrations}

For both elements, we considered in our study i) $V_{O}$ and $V_{T i}$ vacancies and ii) the $T i_{i}$ and $O_{i}$ interstitial species (these latter were inserted at a position equivalent to the $4 c$ Wyckoff position of the $P 4_{2} / m n m$ regular rutile structure (i.e., $(0,1 / 2,0)$ position) and relaxed in the supercell. $\mathrm{Ti}_{\mathrm{i}}$ turn out to be 6-fold coordinated with Ti-O distances of ca. $2.02 \AA$; $\mathrm{O}_{\mathrm{i}}$ tend to form $\mathrm{O}_{2}$ dimers (ca. $1.46 \AA$ ) by moving towards oxygen of the ideal host lattice). The defect formation enthalpies (DFEs) are summarized in Figure 2 for O-poor (T-rich) and O-rich (Ti-poor) synthesis conditions. Defect concentrations are depicted in Figure 3.

From the examination of Figure 2, it appears that oxygen and titanium vacancies, regardless the synthesis conditions are stable only at the charge states +2 and -4 , respectively if the Fermi level is positioned in the $\mathrm{TiO}_{2}$ gap. This result fits nicely with previous HSE calculations. ${ }^{7,11}$ Namely, $\epsilon(+2 /+1)$ and $\epsilon(+1 / 0)$ levels associated to $V_{O}$ species almost overlap and are located just above the bottom of the conduction band. Consequently, if $V_{O}$ and $V_{O}^{+1}$ would exist, they would have the propensity to retrocede their electron(s) to the host lattice triggering the reduction of $\mathrm{Ti}^{4+}$ species into $\mathrm{Ti}^{3+}$ ones, the conduction band being built mainly on the $3 d$-orbitals of titanium. In a similar way, the $\epsilon(0 /-1), \epsilon(-1 /-2), \epsilon(-2 /-3)$ and $\epsilon(-3 /-4)$ levels associated to $V_{T i}$ defect are just below the top of the valence band. However, they are so high in enthalpy that they are unlikely to be created. Moreover, the $\epsilon(+4 /+2)$ and $\epsilon(+2 / 0)$ transition levels of $T i_{i}$ are determined at $0.58 \mathrm{eV}$ below and $0.1 \mathrm{eV}$ above the $\mathrm{CBM}$, respectively; $T i_{i}^{+}$and $T i_{i}^{+3}$ species turn to be thermodynamical unstable and tend to disproportionate at the thermodynamical equilibrium into $T i_{i}^{0}$ and $T i_{i}^{+2}$, and $T i_{i}^{+2}$ and $T i_{i}^{+4}$, respectively. $\mathrm{O}_{\mathrm{i}}$ may present a 0 or -2 charge states with a $\epsilon(0 /-2)$ level located in the mid-gap (i.e., $1.84 \mathrm{eV}$ above the VB).

Under O-poor atmosphere, the Fermi level is expected to lie above $2.61 \mathrm{eV}$ : for lower $E_{F}$ values, $T i_{i}$ species would tend to be formed spontaneously due to negative DFEs leading to a titanium over-stoichiometric material. In the domain defined between $2.61 \mathrm{eV}$ and the CBM, as titanium interstitials present a lesser DFE than oxygen vacancies, $T i_{i}$ point defects are expected to exist in highest concentrations and would be at the origin of the $n$-typeness of $\mathrm{TiO}_{2}$ rather than $V_{O}$. This assumption is validated by our assessment of defect concentrations depicted in Figure 3a. For 
example, considering $T_{g r}=1000 \mathrm{~K}$, we found $E_{F}^{g r}=2.96 \mathrm{eV},\left[T i_{i}\right]=8.43 \times 10^{17} \mathrm{~cm}^{-3}$ and $\left[V_{O}\right]=$ $9.68 \times 10^{14} \mathrm{~cm}^{-3}$ (three order of magnitude less for $\left[V_{O}\right]$ compared to $\left[T i_{i}\right]$ ).

(a) Ti-rich/O-poor

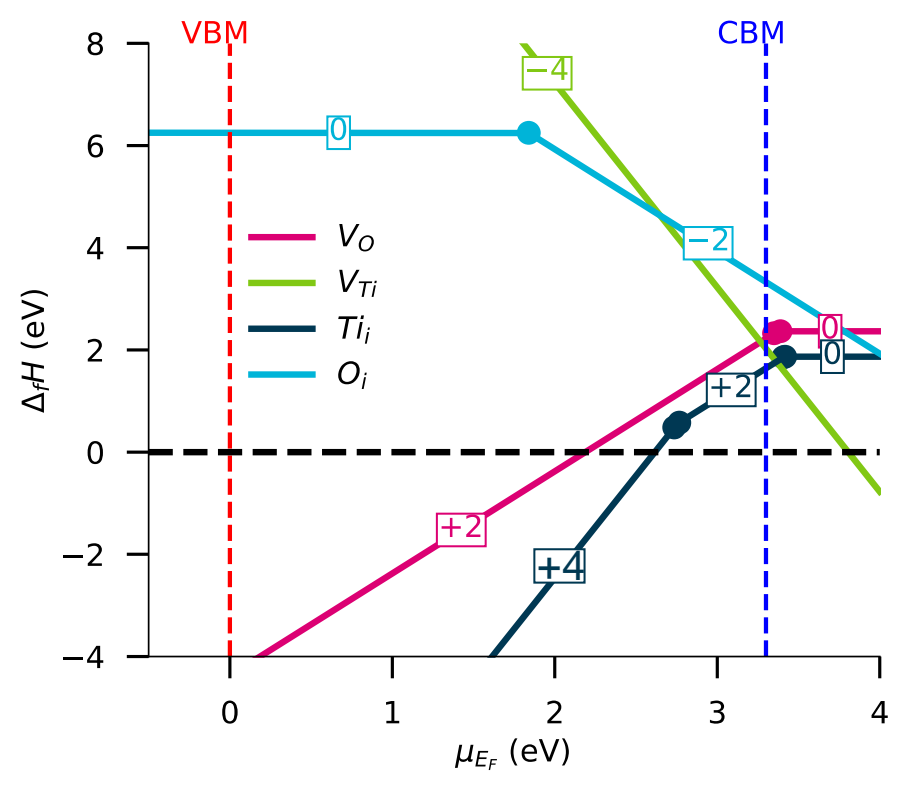

(b) Ti-poor/O-rich

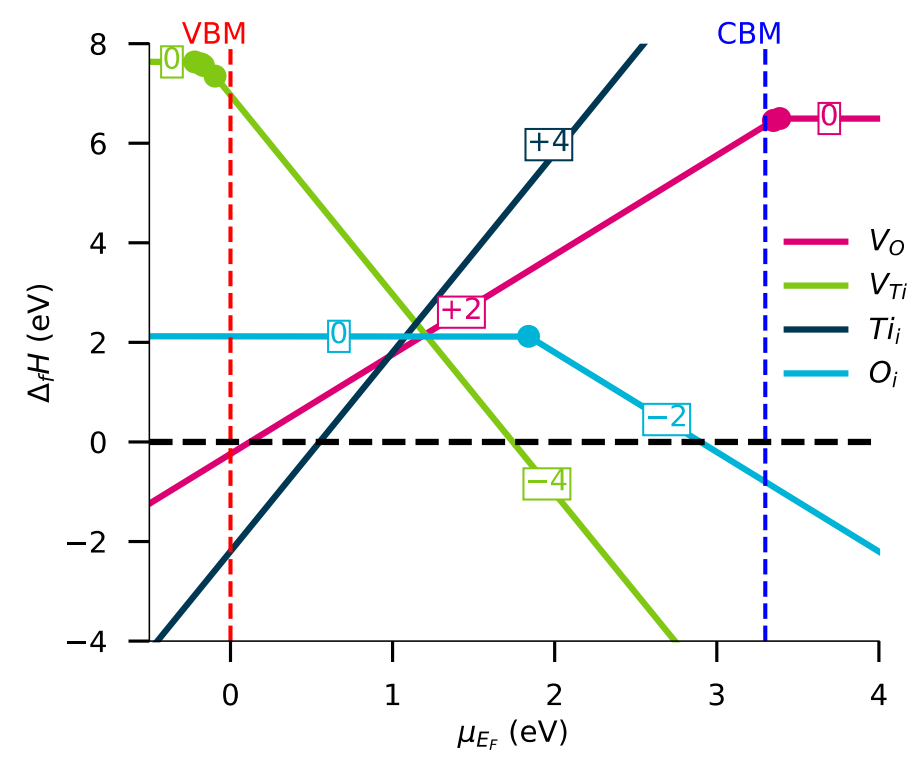

Figure 2: Formation enthalpies of the intrinsic defects in $\mathrm{TiO}_{2}$ vs. $\mu_{E_{F}}$ in (a) Ti-rich/O-poor and (b) Ti-poor/O-rich synthesis conditions 
(a) Ti-rich/O-poor

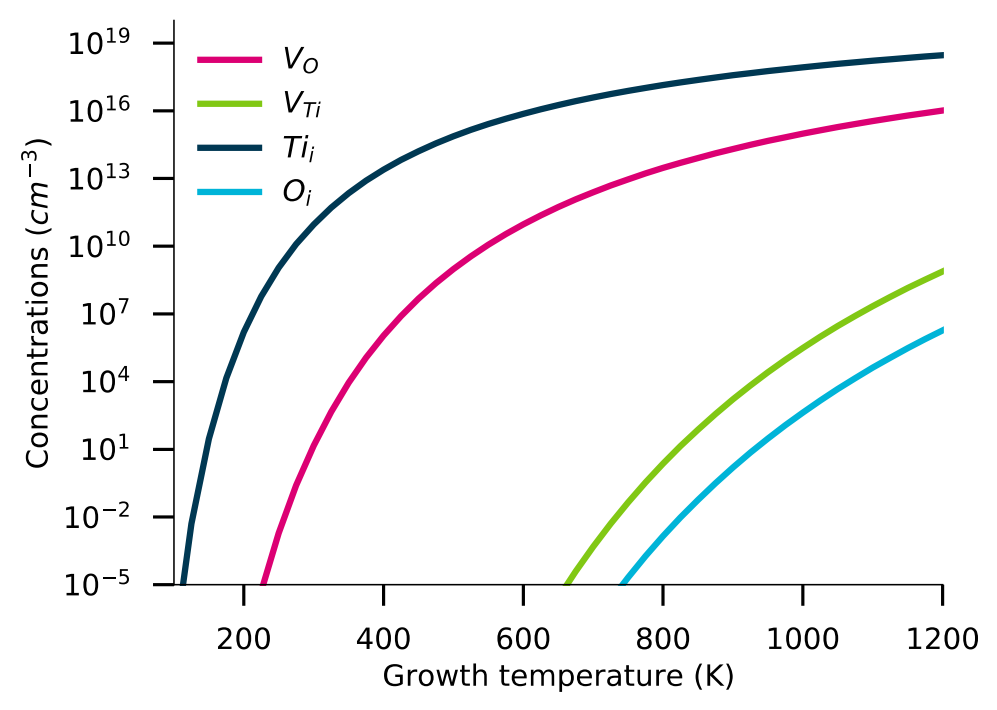

(b) Ti-poor/O-rich

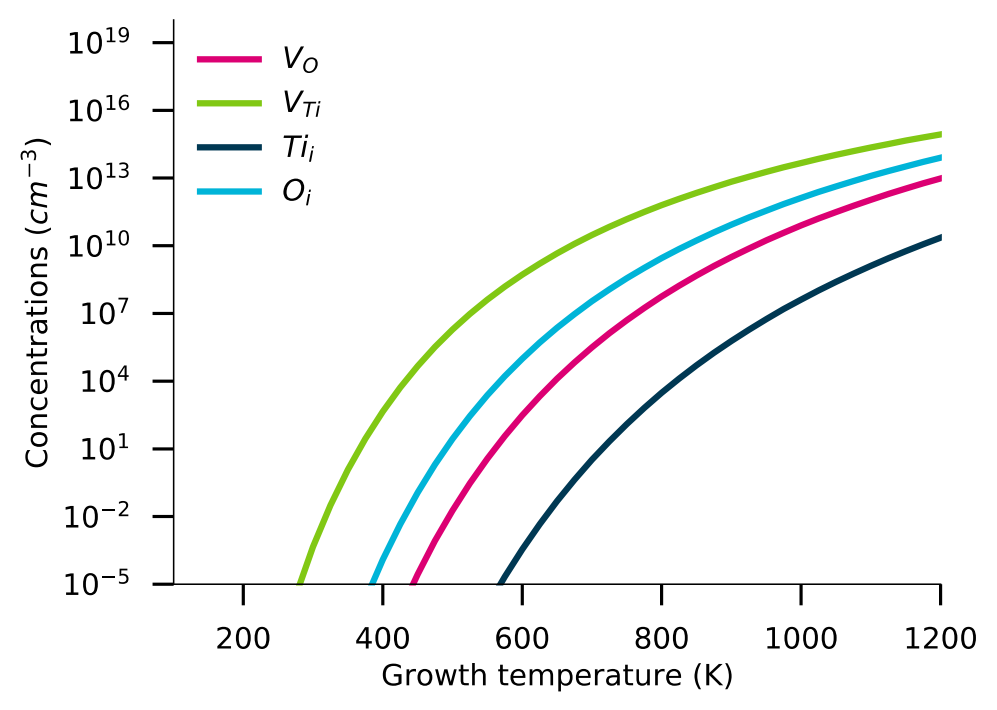

Figure 3: Defect concentrations vs. growth temperature in (a) Ti-rich/O-poor and (b) Ti-poor/Orich atmospheres.

Under O-rich atmosphere, the Fermi level at room temperature is expected to range in the [0.54-1.74] eV energy domain defined by the intercept of the $\mu_{E_{F}}$ axis with the formation enthalpies of $T i_{i}$ and $V_{T i}$ species. This agrees well with previous HSE results. ${ }^{11}$ As aforementioned, a negative formation enthalpy associated to a defect would conduct to the elimination of the $\mathrm{TiO}_{2}$ phase at the benefit of richer or poorer Ti phases. Consequently, in Ti-poor synthesis conditions, rutile $\mathrm{TiO}_{2}$ is expected to be a material with no interesting conductive properties. By setting $T_{g r}$ at $1000 \mathrm{~K}$, we 
determined $E_{F}^{g r}$ at $1.30 \mathrm{eV},\left[V_{T i}\right]=4.65 \times 10^{13} \mathrm{~cm}^{-3}$ and $\left[O_{i}\right]=1.32 \times 10^{12} \mathrm{~cm}^{-3}$. The evolution of concentrations $v s$. the growth temperature is given in Figure $3 \mathrm{~b}$.

We conclude that our simulations performed at the SCAN level follow very well the results obtained considering hybrid functionals. More specifically, we evidence that titanium interstitials constitute in oxygen poor condition the dominant defect responsible for the n-type character of $\mathrm{TiO}_{2}$. Under O-rich atmospheres, we evidenced a deep dopability domain delimited by Ti vacancies and interstitials that cannot lead to a n-type semiconductor.

In the following, we will examine specifically Ti-poor/O-rich synthesis conditions to naturally favor the insertion of dopants at $\mathrm{Ti}$ sites. We emphasize the fact that the choice of synthesis conditions does not alter at all the position of transition levels $\epsilon\left(q / q^{\prime}\right)$ of inserted dopants, i.e., their redox potentials, for which the prediction constitutes the main purpose of this study. Calculations devoted to the $\mathrm{Ti} / \mathrm{V}$ substitution is first presented, and discussion is then enlarged to other TM dopants i.e., manganese, iron, nickel and copper elements.

\section{Transition metal impurities}

The bcc-V phase was used to set the standard chemical potential reference $\mu_{V}^{0}$. The stability domain of rutile $\mathrm{TiO}_{2}$ in presence of vanadium has been calculated and is depicted by dashed area in SI Figure 1-2 as a function of chemical potential variations $\Delta \mu_{T i}, \Delta \mu_{O}$ and $\Delta \mu_{V}$. The stability domain shows four summits, each of them being associated to the competition with potential subproducts. Defect formation enthalpies have been determined in O-rich synthesis conditions only for various charge states of substituted vanadium species denoted $V_{T i}^{n}, n$ varying from +1 (corresponding to formal $\mathrm{V}^{5+}$ species replacing a $\mathrm{Ti}^{4+}$ species) to -2 (formal $\mathrm{V}^{2+}$ ). The evolution of DFEs $v s . \mu_{E_{F}}$ is depicted in Figure 4 where vanadium at titanium site is denoted $V_{T i}$.

Here, the $\epsilon(+1 / 0)$ and $\epsilon(0 /-1)$ transition levels associated to $V_{T i}$ defects were found within the band gap of $\mathrm{TiO}_{2}$ at 2.11 and $2.43 \mathrm{eV}$ from the VBM, respectively. The $\epsilon(-1 /-2)$ level appear well above the CBM $(0.48 \mathrm{eV})$ and is excluded from our considerations. We conclude that formal $\mathrm{V}^{5+}\left(\right.$ i.e., $\left.V_{T i}^{+}\right), \mathrm{V}^{4+}\left(\right.$ i.e., $V_{T i}^{0}$ ), and $\mathrm{V}^{3+}\left(\right.$ i.e., $\left.V_{T i}^{-}\right)$,) species may be a priori found within $\mathrm{TiO}_{2}$ rutile (as reported by Mizushima et al. ${ }^{44}$ ) depending on the synthesis atmosphere, the dopability domain of $\mathrm{TiO}_{2}$ shifting continuously from the $0.54-1.74 \mathrm{eV}$ window to the $2.61-3.30 \mathrm{eV}$ one by modifying the synthesis conditions. Hence, in O-rich and O-poor atmospheres, three charged states 
are stabilized for the substitution of titanium by vanadium. The stabilization of $\mathrm{V}^{4+}$ cations will require intermediate synthesis conditions. Moreover, let us mention here that calculations of defect concentrations (see Figure 5) for a hypothetical V doped $\mathrm{TiO}_{2}$ compound synthesized at $1000 \mathrm{~K}$ under $\mathrm{O}_{2}$ rich atmosphere and quenched to RT lead naturally to $\left[\mathrm{Va}_{T i}\right]=4.21 \times 10^{19} \mathrm{~cm}^{-3}$ and $\left[V_{T i}\right]$ $=1.05 \times 10^{19} \mathrm{~cm}^{-3}$, i.e., the exact and expected $\left[V a_{T i}\right] /\left[V_{T i}\right]$ ratio of 4 for the $\mathrm{Ti}^{4+}{ }_{1-\mathrm{x}} \mathrm{V}^{5+}{ }_{\mathrm{y}} \mathrm{y}_{\mathrm{y} / 4} \mathrm{O}^{2-}{ }_{2}$ charge balance ( $\square$ denotes a Ti vacancy). Extra defects (i.e., $V_{O}, O_{i}$ and $T i_{i}$ ) are several orders of magnitude lesser.

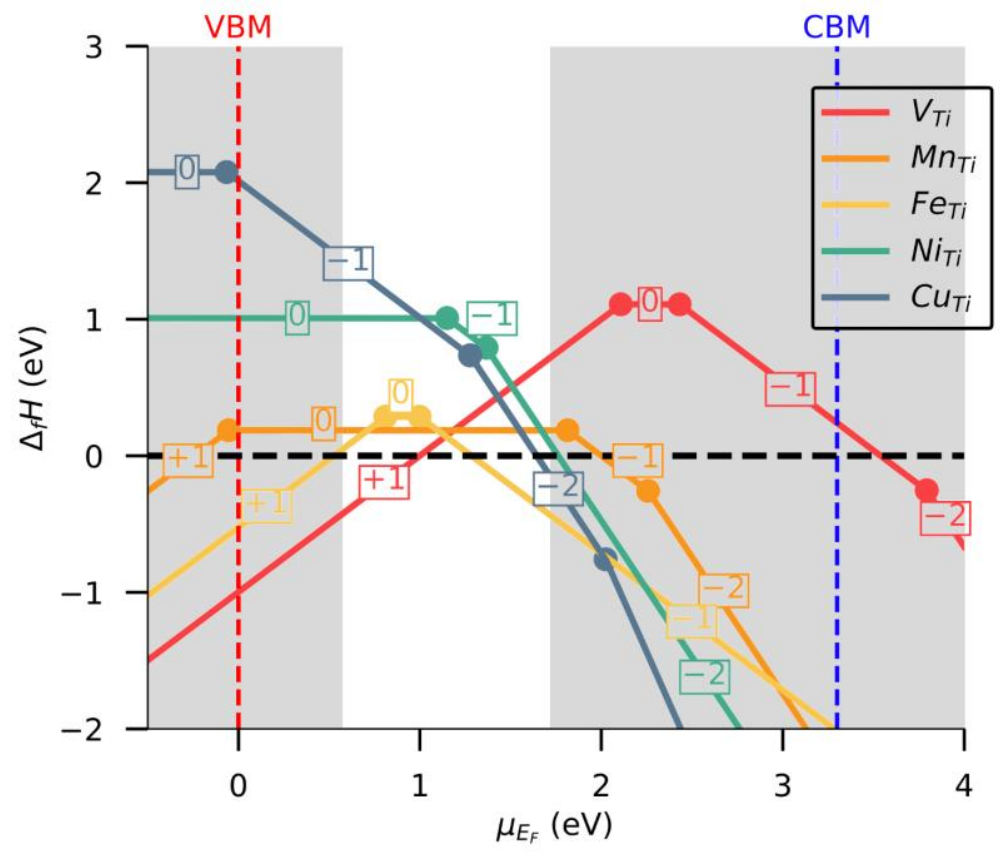

Figure 4: Defect formation enthalpies for TM substitutions under O-rich atmosphere. The dopability domain defined by intrinsic species is delimited by grey blocks. The transition level positions would be calculated at the same energy in O-poor atmosphere, but DFE would be different.

A reasoning similar to the one used for vanadium can be applied to other dopants to anticipate their possible oxidation states once substituted to titanium. The resulting phase diagrams are given in SI, supported by a detailed list of binary and ternary competitive phases. DFEs for TM dopants are reported in Figure 4 for the oxygen rich atmosphere only. In this specific condition, all TMs present DFEs lower than $1.5 \mathrm{eV}$ confirming experimental observations that conclude to the ease to substitute $\mathrm{Ti}$ atoms. 


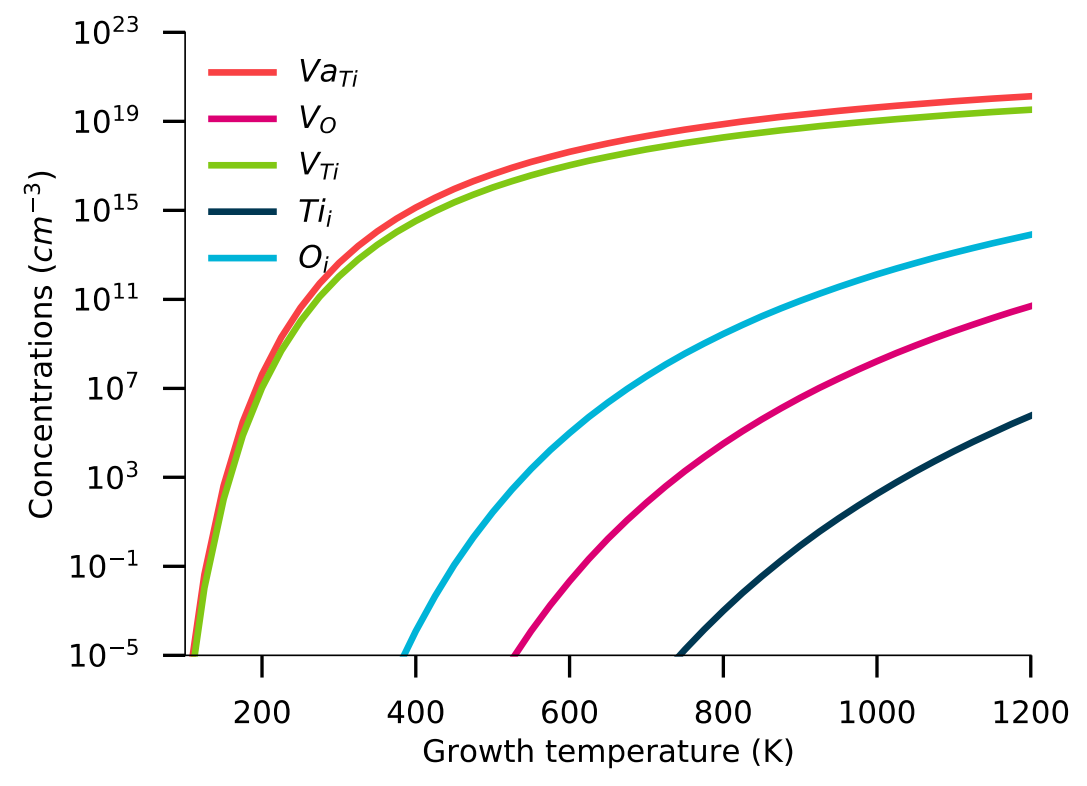

Figure 5: Defect concentrations vs. growth temperature for intrinsic and vanadium impurities point defects. Titanium vacancies and vanadium substitutions are denoted $V_{T i}$ and $V a_{T i}$, respectively.

Figure 6a gathers the estimated transition levels calculated at the thermodynamic equilibrium, i.e., after geometrical relaxation of the atomic positions whatever the charge state of the defects, for all sound TMs.

a)

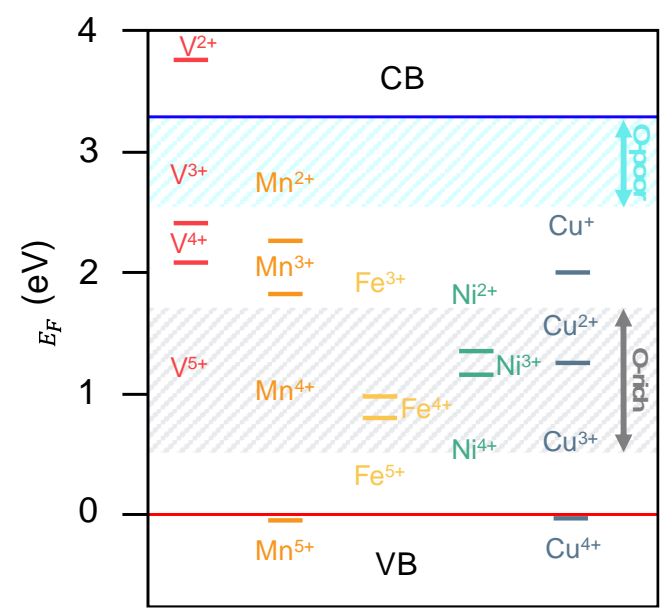

b)

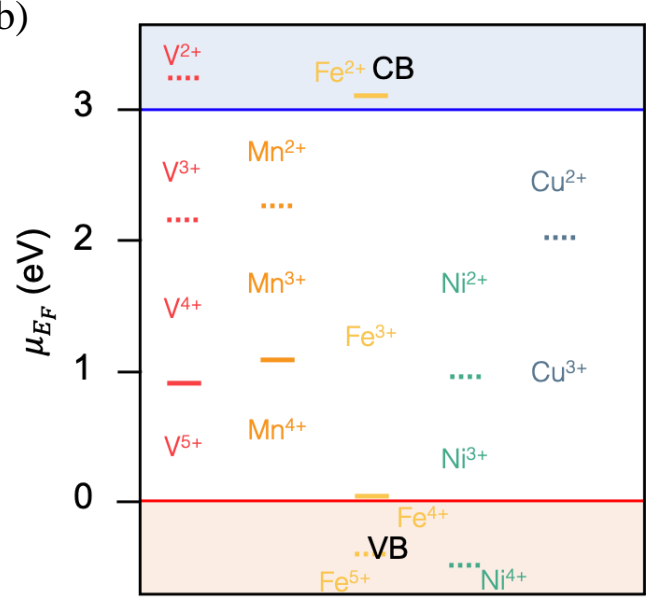

Figure 6: a) Calculated charge transition levels. O-poor and O-rich dopability domains are evidenced by cyan and grey areas, respectively. b) Charge transition levels proposed by Mizushima et al. based on semi-empirical calculations ${ }^{44}$ and photocurrent measurements ${ }^{47}$ represented by dotted and solid lines, respectively. 
Stability domains determined for each O-poor and O-rich extreme limit synthesis conditions, are depicted by hashed colored areas. The following levels can be found located within the bandgap: i) $\epsilon(+1 / 0)$ at $2.11 \mathrm{eV}$ and $\epsilon(0 /-1)$ at $2.43 \mathrm{eV}$ for $\mathrm{V}$, ii) $\epsilon(0 /-1)$ at $1.82 \mathrm{eV}$ and $\epsilon(-1 /-2)$ at $2.26 \mathrm{eV}$ for $\mathrm{Mn}$, iii) $\epsilon(+1 / 0)$ at $0.81 \mathrm{eV}$ and $\epsilon(0 /-1)$ at $1.00 \mathrm{eV}$ for Fe, iv) $\epsilon(0 /-1)$ at $1.15 \mathrm{eV}$ and $\epsilon(-1 /-2)$ at $1.37 \mathrm{eV}$ for $\mathrm{Ni}$, and $\mathrm{v}) \epsilon(-1 /-2)$ at $1.28 \mathrm{eV}$ and $\epsilon(-2 /-3)$ at 2.02 $\mathrm{eV}$ for $\mathrm{Cu}$. From the examination of Figure $6 \mathrm{a}$, we could predict that formal $\mathrm{V}^{3+}\left(\right.$ i.e., $\left.V_{T i}^{-}\right), \mathrm{Mn}^{2+}$ (i.e., $\mathrm{Mn}_{\mathrm{Ti}}^{-2}$ ), $\mathrm{Fe}^{3+}\left(\right.$ i.e., $\mathrm{Fe}_{\mathrm{Ti}}^{-}$), $\mathrm{Ni}^{2+}\left(\right.$ i.e., $\left.\mathrm{Ni}_{\mathrm{Ti}}^{-2}\right)$ and $\mathrm{Cu}^{+}\left(\right.$i.e., $\mathrm{Cu}_{\mathrm{Ti}}^{-3}$ ) species can be formed under $\mathrm{O}-$ poor atmosphere, while formal $\mathrm{V}^{5+}\left(\right.$ i.e., $\left.V_{T i}^{+}\right), \mathrm{Mn}^{4+}\left(\right.$ i.e., $\left.M n_{T i}^{0}\right), \mathrm{Fe}^{5+}\left(\right.$ i.e., $\left.F e_{T i}^{+}\right), \mathrm{Fe}^{4+}\left(\right.$ i.e., $F e_{T i}^{0}$ ), $\mathrm{Fe}^{3+}\left(\right.$ i.e., $\left.F e_{T i}^{-}\right), \mathrm{Ni}^{4+}\left(\right.$ i.e., $\left.N i_{T i}^{0}\right), \mathrm{Ni}^{3+}\left(\right.$ i.e., $\left.N i_{T i}^{-}\right), \mathrm{Ni}^{2+}$ (i.e., $\left.N i_{T i}^{-2}\right), \mathrm{Cu}^{3+}\left(\right.$ i.e., $C u_{T i}^{-}$), and $\mathrm{Cu}^{2+}($ i.e., $\left.C u_{T i}^{-2}\right)$ species can be stabilized in O-rich atmosphere. For intermediate synthesis situations, formal $\mathrm{V}^{5+}, \mathrm{V}^{4+}$ and $\mathrm{V}^{3+}, \mathrm{Mn}^{4+}, \mathrm{Mn}^{3+}$ and $\mathrm{Mn}^{2+}, \mathrm{Fe}^{3+}, \mathrm{Ni}^{2+}$, and $\mathrm{Cu}^{2+}$ and $\mathrm{Cu}^{+}$(see white zone in-between the $\mathrm{O}$-poor and $\mathrm{O}$-rich domains) may exist in the $\mathrm{TiO}_{2}$ host lattice in contrast with formal $\mathrm{V}^{2+}, \mathrm{Fe}^{2+}$ (transition level find above $5 \mathrm{eV}$ ), $\mathrm{Mn}^{5+}$ or $\mathrm{Cu}^{4+}$ species for instance. Let us notice that a mixed valence may be observed if the Fermi level is pinned in the direct neighboring of a transition level $\epsilon\left(q / q^{\prime}\right)$.

Many experimental studies reported on the synthesis and the characterization of $3 d$ TM doped rutile $\mathrm{TiO}_{2}$ materials. ${ }^{26,36,39,40,43-45,47,51,83-91}$ Figure $6 \mathrm{~b}$ sums up the domain limits of cationic species in this specific host material as proposed by Mizushima et al. ${ }^{43-45,47}$ based on experimental (e.g., photocurrent) and theoretical (semi-empirical model supported by photoconductivity and photo-ESR measurements) considerations. Namely, experimentally observed ionic species in $\mathrm{TiO}_{2}$ rutile, i.e., $\mathrm{V}^{5+}, \mathrm{V}^{4+}$ and $\mathrm{V}^{3+26,44,51}, \mathrm{Mn}^{4+}, \mathrm{Mn}^{3+}$ and $\mathrm{Mn}^{2+47,51,83-85}, \mathrm{Fe}^{4+}$ and $\mathrm{Fe}^{3+39,43,47,51,86,88,91}$, $\mathrm{Cu}^{2+}$ and possibly $\mathrm{Cu}^{+89,90}$, and $\mathrm{Ni}^{3+}$ and $\mathrm{Ni}^{2+36,40,51}$, possibly stabilized for different material's shape (nanorods, nanopowders, thin films) are predicted from our simulations. Nevertheless, it has to be noticed that discrepancies exist between theory and experiments. Namely, it is has be noticed that $\mathrm{Fe}^{2+}$ doped $\mathrm{TiO}_{2}$ (rutile form) has been reported this last decade, ${ }^{35,39,87,91}$ contradicting both Mizushima and ours predictions where the $\epsilon(-1 /-2)$ level $\left(\mathrm{Fe}^{3+} / \mathrm{Fe}^{2+}\right.$ borderline $)$ lies within the CB (not represented in Figure 6a). This may originate from specific out-of-equilibrium synthesis conditions (beam epitaxy, ball milled, magnetron sputtering) used to stabilize this doped variety. Concerning the lack of detected $\mathrm{Fe}^{5+}, \mathrm{Ni}^{4+}$ and $\mathrm{Cu}^{3+}$ species in doped $\mathrm{TiO}_{2}$ materials, we may advocate, if calculations are correct, that high enough oxidizing atmospheres have not be used so 
far to stabilize them, but their existence should be conceivable. Mizushima et al. refute this possibility. At the end, $\mathrm{Cu}^{+}$doped $\mathrm{TiO}_{2}$ probably exists ${ }^{90}$ in good agreement with Figure 6 a even if not reported in Figure $6 b$.

At this stage let us mention that the comparison between Figure $6 a$ and Figure $6 \mathrm{~b}$ (beyond the energy (potential) domains of existence) may be truncated for multiple reasons. Concerning the semi-empirical simulations ${ }^{44}$, it is worth to note that the model used (proposed by Alen ${ }^{46}$ ) is notably based on electrostatic interactions between $d$ electrons described through parameters arbitrarily sets, extrapolated or taken from other metal organic compounds. These simulated data have been compared to photoconductivity and photo-ESR measurements which allow to access the stability region of charged impurities. During such experiments, the variation of the Fermi level position was controlled for some $\mathrm{TM}$ substituted $\mathrm{TiO}_{2}$ samples via the insertion of $\mathrm{Li}^{+}$cations or changing the oxygen content in the synthesis conditions to stabilize preferentially a given oxidation state of the probed element. Thenceforth, the redox $E\left(D^{n} / D^{n+1}\right)$ potential can be perturbed compared to the ideal situation treated via calculations, the short-range environment of the dopant being perturbed itself.

On our theoretical side, the overall defected structure was drastically simplified in our calculations by tuning the charge state of defects (so the oxidation states of impurities) by changing the global electrical charge of the system and applying a Jellium-like model. Moreover, the control of unintentional defects is a critical point when experiments are performed. These ones may condense to form complexes also not taken into account here. Concerning the calculation method, the recently developed SCAN functional indicate several advantages for the prediction of electronic properties with respect to GGA approaches. Indeed, key physical data have been reported to be significantly improved for a large panel of materials, and accuracy is (sometimes) similar with hybrid methods. ${ }^{92-94}$ A Hubbard correction could improve the description of point defects and impact their transition levels positions. This remains beyond the scope of this study but should be considered for future investigations.

\section{Conclusion}

Chemically speaking, a transition level $\epsilon\left(q / q^{\prime}\right)$ for the specific case of a dopant D delimits the existence domain in energy between the $\mathrm{D}^{\mathrm{n}}$ and the $\mathrm{D}^{\mathrm{n}+1}$ species. Consequently, this level has to be regarded as the redox potential $E\left(D^{n} / D^{n+1}\right)$ of the redox $D^{n} / D^{n+1}$ couple for a dopant $D$ 
embedded in a given host lattice. This potential will strongly depend upon the chemical environment of the dopant (i.e., the coordination number, the chemical nature of the ligands, the covalency of the chemical bond, etc.) and will change from one host lattice to another. Indeed, $a b$ initio calculations can serve to evaluate the potential towards the bottom of the conduction band or the top of the valence band via the determination of $\epsilon\left(q / q^{\prime}\right)$, and consequently towards an absolute scale if the BV or BC position with respect to vacuum level (or standard hydrogen electrode for instance) has been experimentally measured. Obviously, the positioning of $\epsilon\left(q / q^{\prime}\right)$ values can be impacted by the nature and the accuracy of the chosen approximations (exchange-correlation functional, size and/or type of basis set, relativistic effects, etc.) for calculations. This is especially true for TM species for which the computation of physical properties is particularly sensitive to these parameters, namely species with single electrons on $d$ orbitals. So far, if the use of accurate approaches remains attractive and performant for this purpose, they suffer from an important computational cost which lets the supercell studies with realistic doping elusive. In that sense, we took benefit of this study to consider the SCAN functional as an alternative for such point defect investigations.

In a more general way, the ab initio determination of the redox potentials of dopants in solids is a contemporary challenge to explain and/or to tune properties of a host lattice and its doped congener. In the specific case of photo-catalysis, the knowledge of these data is crucial to orientate syntheses and uses. Of course, domains of interest are not limited to only this area.

DFT calculations based on the SCAN functional have been done on doped rutile $\mathrm{TiO}_{2}$ phase used as a school case. However, the procedure can be extrapolated to any semiconductors and insulators. Once, the electronic gap and the external dopability limit determined, stability of dopants can be probed in the host lattice versus different synthetic conditions, their attainable oxidation states determined, and their associated redox potential calculated. If accurate electronic information (e.g., electron affinity) on the host lattice are known, potential on an absolute scale can be extrapolated.

\section{Acknowledgments}

This work was performed using CCIPL (Centre de Calculs Intensifs des Pays de la Loire) and HPC resources from GENCI-TGCC (Grant 2020-A0080911491). W.L.-D.-H. particularly thanks the financial support by the ANR-18-CE08-0012 PERSIST project of the French National 
Research Agency and the CNRS. W.L.-D.-H. is also very grateful to Dr. Adrien Stoliaroff for his help on the use of the PyDEF software ${ }^{70,71}$ and useful discussions. Crystal structures were represented using the VESTA software. ${ }^{95}$

\section{Supporting Informations}

Details on the corrections for the defect formation enthalpies, stability domains and concentrations of TM-doped rutile $\mathrm{TiO}_{2}$; representation of the electronic charge density associated to point defects for a representative set of defects species. 


\section{References}

(1) Cronemeyer, D. C. Electrical and Optical Properties of Rutile Single Crystals. Phys. Rev. 1952, 87 (5), 876-886. https://doi.org/10.1103/PhysRev.87.876.

(2) Breckenridge, R. G.; Hosler, W. R. Electrical Properties of Titanium Dioxide Semiconductors. Phys. Rev. 1953, 91 (4), 793-802. https://doi.org/10.1103/PhysRev.91.793.

(3) Cronemeyer, D. C. Infrared Absorption of Reduced Rutile $\mathrm{TiO}_{2}$ Single Crystals. Phys. Rev. 1959, 113 (5), 1222-1226. https://doi.org/10.1103/PhysRev.113.1222.

(4) Yahia, J. Dependence of the Electrical Conductivity and Thermoelectric Power of Pure and Aluminum-Doped Rutile on Equilibrium Oxygen Pressure and Temperature. Phys. Rev. 1963, 130 (5), 1711-1719. https://doi.org/10.1103/PhysRev.130.1711.

(5) Kobayashi, K.; Takata, M.; Fujimura, Y.; Okamoto, S. Investigation of Trapping States in a Nb-doped Rutile by Admittance Spectroscopy. J. Appl. Phys. 1986, 60 (12), 4191-4196. https://doi.org/10.1063/1.337505.

(6) Yagi, E.; Hasiguti, R. R.; Aono, M. Electronic Conduction above 4 K of Slightly Reduced Oxygen-Deficient Rutile $\mathrm{TiO}_{2}$. Phys. Rev. $B$ 1996, 54 (11), 7945-7956. https://doi.org/10.1103/PhysRevB.54.7945.

(7) Janotti, A.; Varley, J. B.; Rinke, P.; Umezawa, N.; Kresse, G.; Van de Walle, C. G. Hybrid Functional Studies of the Oxygen Vacancy in $\mathrm{TiO}_{2}$. Phys. Rev. B 2010, 81 (8), 085212. https://doi.org/10.1103/PhysRevB.81.085212.

(8) Mattioli, G.; Alippi, P.; Filippone, F.; Caminiti, R.; Amore Bonapasta, A. Deep versus Shallow Behavior of Intrinsic Defects in Rutile and Anatase $\mathrm{TiO}_{2}$ Polymorphs. J. Phys. Chem. C 2010, 114 (49), 21694-21704. https://doi.org/10.1021/jp1041316.

(9) Morgan, B. J.; Watson, G. W. Intrinsic N-Type Defect Formation in $\mathrm{TiO}_{2}$ : A Comparison of Rutile and Anatase from GGA+U Calculations. J. Phys. Chem. C 2010, 114 (5), 2321-2328. https://doi.org/10.1021/jp9088047.

(10) Lee, H.-Y.; Clark, S. J.; Robertson, J. Calculation of Point Defects in Rutile $\mathrm{TiO}_{2}$ by the Screened-Exchange Hybrid Functional. Phys. Rev. B 2012, 86 (7), 075209. https://doi.org/10.1103/PhysRevB.86.075209.

(11) Bjørheim, T. S.; Kuwabara, A.; Norby, T. Defect Chemistry of Rutile $\mathrm{TiO}_{2}$ from First Principles Calculations. J. Phys. Chem. C 2013, 117 (11), 5919-5930. https://doi.org/10.1021/jp304146e.

(12) Deák, P.; Aradi, B.; Frauenheim, T. Oxygen Deficiency in $\mathrm{TiO}_{2}$ : Similarities and Differences between the Ti Self-Interstitial and the O Vacancy in Bulk Rutile and Anatase. Phys. Rev. B 2015, 92 (4), 045204. https://doi.org/10.1103/PhysRevB.92.045204.

(13) Zainullina, V. M.; Zhukov, V. P.; Korotin, M. A. Influence of Oxygen Nonstoichiometry and Doping with 2p-, 3p-, 6p- and 3d-Elements on Electronic Structure, Optical Properties and Photocatalytic Activity of Rutile and Anatase: Ab Initio Approaches. J. Photochem. $\begin{array}{llllll}\text { Photobiol. } & C & \text { Photochem. } & \text { 2015, } & \text { 58-83. }\end{array}$ 
https://doi.org/10.1016/j.jphotochemrev.2014.10.005.

(14) Zimmermann, C.; Bonkerud, J.; Herklotz, F.; Sky, T. N.; Hupfer, A.; Monakhov, E.; Svensson, B. G.; Vines, L. Influence of Annealing Atmosphere on Formation of ElectricallyActive Defects in Rutile $\mathrm{TiO}_{2} . \quad J$. Appl. Phys. 2018, 123 (16), 161572. https://doi.org/10.1063/1.5011136.

(15) Han, X.; Amrane, N.; Zhang, Z.; Benkraouda, M. Insights into the Characteristic Gap Level and N-Type Conductivity of Rutile $\mathrm{TiO}_{2}$ from the Hybrid Functional Method. J. Phys. Chem. C 2019, 123 (4), 2037-2047. https://doi.org/10.1021/acs.jpcc.8b09766.

(16) Zunger, A. Electronic Structure of 3d Transition-Atom Impurities in Semiconductors. In Solid State Physics; Ehrenreich, H., Turnbull, D., Eds.; Academic Press, 1986; Vol. 39, pp 275-464. https://doi.org/10.1016/S0081-1947(08)60371-9.

(17) Kreissl, J.; Schulz, H.-J. Transition-Metal Impurities in II-VI Semiconductors: Characterization and Switching of Charge States. J. Cryst. Growth 1996, 161 (1), 239-249. https://doi.org/10.1016/0022-0248(95)00665-6.

(18) Neumark, G. F. Defects in Wide Band Gap II-VI Crystals. Mater. Sci. Eng. R Rep. 1997, 21 (1), iii-46. https://doi.org/10.1016/S0927-796X(97)00008-9.

(19) Van de Walle, C. G. Defects and Impurities in Semiconductors. In Handbook of Materials Modeling: Methods; Yip, S., Ed.; Springer Netherlands: Dordrecht, 2005; pp 1877-1888. https://doi.org/10.1007/978-1-4020-3286-8_96.

(20) Feichtinger, H. Deep Centers in Semiconductors. In Handbook of Semiconductor Technology; John Wiley \& Sons, Ltd, 2008; pp 167-229. https://doi.org/10.1002/9783527621842.ch4.

(21) Yamashita, H.; Ichihashi, Y.; Takeuchi, M.; Kishiguchi, S.; Anpo, M.; IUCr. Characterization of Metal Ion-Implanted Titanium Oxide Photocatalysts Operating under Visible Light Irradiation. J. Synchrotron Radiat. 1999. https://doi.org/10.1107/S0909049598017257.

(22) Kim, D. H.; Lee, K. S.; Kim, Y.-S.; Chung, Y.-C.; Kim, S.-J. Photocatalytic Activity of Ni $8 \mathrm{Wt} \%$-Doped $\mathrm{TiO}_{2}$ Photocatalyst Synthesized by Mechanical Alloying Under Visible Light. J. Am. Ceram. Soc. 2006, 89 (2), 515-518. https://doi.org/10.1111/j.1551-2916.2005.00782.x.

(23) Mohamed, M. M.; Al-Esaimi, M. M. Characterization, Adsorption and Photocatalytic Activity of Vanadium-Doped $\mathrm{TiO}_{2}$ and Sulfated $\mathrm{TiO}_{2}$ (Rutile) Catalysts: Degradation of Methylene Blue Dye. J. Mol. Catal. Chem. 2006, 255 (1), 53-61. https://doi.org/10.1016/j.molcata.2006.03.071.

(24) Zhou, J.; Takeuchi, M.; Zhao, X. S.; Ray, A. K.; Anpo, M. Photocatalytic Decomposition of Formic Acid Under Visible Light Irradiation Over V-Ion-Implanted $\mathrm{TiO}_{2}$ Thin Film Photocatalysts Prepared on Quartz Substrate by Ionized Cluster Beam (ICB) Deposition Method. Catal. Lett. 2006, 106 (1), 67-70. https://doi.org/10.1007/s10562-005-9192-5.

(25) Zhou, J.; Takeuchi, M.; Ray, A. K.; Anpo, M.; Zhao, X. S. Enhancement of Photocatalytic Activity of $\mathrm{P} 25 \mathrm{TiO}_{2}$ by Vanadium-Ion Implantation under Visible Light Irradiation. J. Colloid Interface Sci. 2007, 311 (2), 497-501. https://doi.org/10.1016/j.jcis.2007.03.007. 
(26) Li, L.; Liu, C.; Liu, Y. Study on Activities of Vanadium (IV/V) Doped $\mathrm{TiO}_{2}$ (R) Nanorods Induced by UV and Visible Light. Mater. Chem. Phys. 2009, 113 (2), 551-557. https://doi.org/10.1016/j.matchemphys.2008.08.009.

(27) Yadav, H. M.; Kolekar, T. V.; Pawar, S. H.; Kim, J.-S. Enhanced Photocatalytic Inactivation of Bacteria on Fe-Containing $\mathrm{TiO}_{2}$ Nanoparticles under Fluorescent Light. J. Mater. Sci. Mater. Med. 2016, 27 (3), 57. https://doi.org/10.1007/s10856-016-5675-8.

(28) De, R.; Haque, S. M.; Tripathi, S.; Rao, K. D.; Singh, R.; Som, T.; Sahoo, N. K. Temperature Dependent Optical Characterization of $\mathrm{Ni}_{-} \mathrm{TiO}_{2}$ Thin Films as Potential Photocatalytic Material. AIP Adv. 2017, 7 (9), 095115. https://doi.org/10.1063/1.4998769.

(29) Zahid, M.; Papadopoulou, E. L.; Suarato, G.; Binas, V. D.; Kiriakidis, G.; Gounaki, I.; Moira, O.; Venieri, D.; Bayer, I. S.; Athanassiou, A. Fabrication of Visible Light-Induced

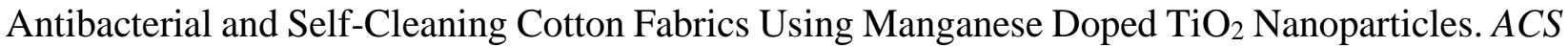
Appl. Bio Mater. 2018, 1 (4), 1154-1164. https://doi.org/10.1021/acsabm.8b00357.

(30) Hao, C.; Lv, H.; Zhao, Q.; Li, B.; Zhang, C.; Mi, C.; Song, Y.; Ma, J. Investigation of $\mathrm{V}$-Doped $\mathrm{TiO}_{2}$ as an Anodic Catalyst Support for SPE Water Electrolysis. Int. J. Hydrog. Energy 2017, 42 (15), 9384-9395. https://doi.org/10.1016/j.ijhydene.2017.02.131.

(31) Chang, J.-H.; Wang, Y.-L.; Dong, C.-D.; Shen, S.-Y. Electrocatalytic Degradation of Azo Dye by Vanadium-Doped $\mathrm{TiO}_{2}$ Nanocatalyst. Catalysts 2020, 10 (5), 482. https://doi.org/10.3390/catal10050482.

(32) Matsumoto, Y.; Murakami, M.; Shono, T.; Hasegawa, T.; Fukumura, T.; Kawasaki, M.; Ahmet, P.; Chikyow, T.; Koshihara, S.; Koinuma, H. Room-Temperature Ferromagnetism in Transparent Transition Metal-Doped Titanium Dioxide. Science 2001, 291 (5505), 854-856. https://doi.org/10.1126/science.1056186.

(33) Wang, Z.; Tang, J.; Tung, L. D.; Zhou, W.; Spinu, L. Ferromagnetism and Transport Properties of Fe-Doped Reduced-Rutile $\mathrm{TiO}_{2}-\delta$ Thin Films. J. Appl. Phys. 2003, 93 (10), 78707872. https://doi.org/10.1063/1.1556122.

(34) Hong, N. H.; Sakai, J.; Hassini, A. Ferromagnetism at Room Temperature with a Large Magnetic Moment in Anatase V-Doped $\mathrm{TiO}_{2}$ Thin Films. Appl. Phys. Lett. 2004, 84 (14), 2602-2604. https://doi.org/10.1063/1.1703848.

(35) Meng, H. J.; Hou, D. L.; Jia, L. Y.; Ye, X. J.; Zhou, H. J.; Li, X. L. Role of Oxygen Vacancies on Ferromagnetism in Fe-Doped $\mathrm{TiO}_{2}$ Thin Films. J. Appl. Phys. 2007, 102 (7), 073905. https://doi.org/10.1063/1.2786115.

(36) Park, Y. R.; Choi, S.; Lee, J. H.; Kim, K. J.; Kim, C. S. Ferromagnetic Properties of Ni-Doped Rutile $\quad \mathrm{TiO}_{2}-\delta . \quad J . \quad$ Korean Phys. Soc. 2007, $50 \quad$ (3), 638-642. https://doi.org/10.3938/jkps.50.638.

(37) Tian, Z. M.; Yuan, S. L.; Yuan, S. J.; Xie, H. Y.; He, J. H.; Wang, Y. Q.; Liu, K. L.; Yin, S. Y. Effect of Annealing Conditions on the Magnetism of Vanadium-Doped $\mathrm{TiO}_{2}$ Powders. Solid State Commun. 2008, 146 (11), 522-525. https://doi.org/10.1016/j.ssc.2008.01.016.

(38) Grau-Crespo, R.; Schwingenschlögl, U. The Interplay between Dopants and Oxygen 
Vacancies in the Magnetism of V-Doped $\mathrm{TiO}_{2}$. J. Phys. Condens. Matter 2011, 23 (33), 334216. https://doi.org/10.1088/0953-8984/23/33/334216.

(39) Mudarra Navarro, A. M.; Rodríguez Torres, C. E.; Bilovol, V.; Fabiana Cabrera, A.; Errico, L. A.; Weissmann, M. Study of the Relation between Oxygen Vacancies and Ferromagnetism in Fe-Doped $\mathrm{TiO}_{2}$ Nano-Powders. J. Appl. Phys. 2014, 115 (22), 223908. https://doi.org/10.1063/1.4883183.

(40) Parveen, B.; Mahmood-ul-Hassan; Khalid, Z.; Riaz, S.; Naseem, S. RoomTemperature Ferromagnetism in Ni-Doped $\mathrm{TiO}_{2}$ Diluted Magnetic Semiconductor Thin Films. $J$. Appl. Res. Technol. 2017, 15 (2), 132-139. https://doi.org/10.1016/j.jart.2017.01.009.

(41) Xia, D.; Hou, Q.; Guan, Y. Effect of Fe Doping and O Vacancies on the Magnetic Properties of Rutile $\mathrm{TiO}_{2}$. J. Supercond. Nov. Magn. 2019, 32 (11), 3615-3621. https://doi.org/10.1007/s10948-019-5129-x.

(42) Hanaor, D. A. H.; Sorrell, C. C. Review of the Anatase to Rutile Phase Transformation. J. Mater. Sci. 2011, 46 (4), 855-874. https://doi.org/10.1007/s10853-010-5113-0.

(43) Mizushima, K.; Iida, S. Photoconductivity Spectra of Fe-Doped $\mathrm{TiO}_{2}$. J. Phys. Soc. Jpn. 1971, 31 (3), 950-950. https://doi.org/10.1143/JPSJ.31.950.

(44) Mizushima, K.; Tanaka, M.; Iida, S. Energy Levels of Iron Group Impurities in $\mathrm{TiO}_{2}$. J. Phys. Soc. Jpn. 1972, 32 (6), 1519-1524. https://doi.org/10.1143/JPSJ.32.1519.

(45) Mizushima, K.; Tanaka, M.; Asai, K.; Iida, S. One Electron Energy Levels of Iron Group Impurities in $\mathrm{TiO}_{2} . \quad A I P$ Conf. Proc. 1974, 18 (1), 1044-1048. https://doi.org/10.1063/1.2947197.

(46) Allen, J. W. Proceeding 7th Int. Conf Semicond. 1964, 781.

(47) Mizushima, K.; Tanaka, M.; Asai, A.; Iida, S.; Goodenough, J. B. Impurity Levels of Iron-Group Ions in $\mathrm{TiO}_{2}$ (II). J. Phys. Chem. Solids 1979, 40 (12), 1129-1140. https://doi.org/10.1016/0022-3697(79)90148-3.

(48) Mo, S.-D.; Lin, L. B.; Lin, D. L. Electron States of Iron Group Impurities in Doped Rutile $\left(\mathrm{TiO}_{2}\right)$. J. Phys. Chem. Solids 1994, 55 (11), 1309-1313. https://doi.org/10.1016/00223697(94)90214-3.

(49) Sangaletti, L.; Mozzati, M. C.; Galinetto, P.; Azzoni, C. B.; Speghini, A.; Bettinelli, M.; Calestani, G. Ferromagnetism on a Paramagnetic Host Background: The Case of Rutile $\mathrm{TM}: \mathrm{TiO}_{2}$ Single Crystals $(\mathrm{TM}=\mathrm{Cr}, \mathrm{Mn}, \mathrm{Fe}, \mathrm{Co}, \mathrm{Ni}, \mathrm{Cu})$. J. Phys. Condens. Matter 2006, 18 (32), 7643-7650. https://doi.org/10.1088/0953-8984/18/32/012.

(50) Matsumoto, Y.; Katayama, M.; Abe, T.; Ohsawa, T.; Ohkubo, I.; Kumigashira, H.; Oshima, M.; Koinuma, H. Chemical Trend of Fermi-Level Shift in Transition Metal-Doped $\mathrm{TiO}_{2}$ Films. J. Ceram. Soc. Jpn. 2010, 118 (1383), 993-996. https://doi.org/10.2109/jcersj2.118.993.

(51) Yamaka, E.; Barnes, R. G. Paramagnetic Resonance of Iron Group Elements in Rutile. I. The $\mathrm{Ti}^{47}$ and $\mathrm{Ti}^{49}$ Hfs Interaction. Phys. Rev. 1964, 135 (1A), A144-A148. https://doi.org/10.1103/PhysRev.135.A144. 
(52) Kernazhitsky, L.; Shymanovska, V.; Gavrilko, T.; Naumov, V.; Kshnyakin, V.; Khalyavka, T. A Comparative Study of Optical Absorption and Photocatalytic Properties of Nanocrystalline Single-Phase Anatase and Rutile $\mathrm{TiO}_{2}$ Doped with Transition Metal Cations. $J$. Solid State Chem. 2013, 198, 511-519. https://doi.org/10.1016/j.jssc.2012.11.015.

(53) Park, S.-G.; Magyari-Köpe, B.; Nishi, Y. Electronic Correlation Effects in Reduced Rutile $\mathrm{TiO}_{2}$ within the LDA+U Method. Phys Rev $B$ 2010, 82 (11), 115109. https://doi.org/10.1103/PhysRevB.82.115109.

(54) Umebayashi, T.; Yamaki, T.; Itoh, H.; Asai, K. Analysis of Electronic Structures of 3d Transition Metal-Doped $\mathrm{TiO}_{2}$ Based on Band Calculations. J. Phys. Chem. Solids 2002, 63 (10), 1909-1920. https://doi.org/10.1016/S0022-3697(02)00177-4.

(55) Saini, M.; Kumar, M.; Som, T. Ab Initio Study of 3d Transition Metal-Doping Effects in Rutile-TiO 2 : Role of Bandgap Tunability in Conductivity Behaviour. Appl. Surf. Sci. 2017, 418, 302-307. https://doi.org/10.1016/j.apsusc.2017.01.262.

(56) Roy, S.; Luitel, H.; Sanyal, D. Enhanced Stability and Ferromagnetic Property in Transition Metals Co-Doped Rutile $\mathrm{TiO}_{2}$. J. Phys. Chem. Solids 2020, 146, 109582. https://doi.org/10.1016/j.jpcs.2020.109582.

(57) Sun, J.; Ruzsinszky, A.; Perdew, J. P. Strongly Constrained and Appropriately Normed Semilocal Density Functional. Phys. Rev. Lett. 2015, 115 (3), 036402. https://doi.org/10.1103/PhysRevLett.115.036402.

(58) Zhang, Y.; Furness, J. W.; Xiao, B.; Sun, J. Subtlety of $\mathrm{TiO}_{2}$ Phase Stability: Reliability of the Density Functional Theory Predictions and Persistence of the Self-Interaction Error. J. Chem. Phys. 2019, 150 (1), 014105. https://doi.org/10.1063/1.5055623.

(59) Kresse, G.; Furthmüller, J. Efficiency of Ab-Initio Total Energy Calculations for Metals and Semiconductors Using a Plane-Wave Basis Set. Comput. Mater. Sci. 1996, 6 (1), 1550. https://doi.org/10.1016/0927-0256(96)00008-0.

(60) Kresse, G.; Furthmüller, J. Efficient Iterative Schemes for Ab Initio Total-Energy Calculations Using a Plane-Wave Basis Set. Phys Rev B 1996, 54 (16), 11169-11186. https://doi.org/10.1103/PhysRevB.54.11169.

(61) Kresse, G.; Joubert, D. From Ultrasoft Pseudopotentials to the Projector Augmented-Wave Method. Phys Rev B 1999, 59 (3), 1758-1775. https://doi.org/10.1103/PhysRevB.59.1758.

(62) Krukau, A. V.; Vydrov, O. A.; Izmaylov, A. F.; Scuseria, G. E. Influence of the Exchange Screening Parameter on the Performance of Screened Hybrid Functionals. J. Chem. Phys. 2006, 125 (22), 224106. https://doi.org/10.1063/1.2404663.

(63) Perdew, J. P.; Burke, K.; Ernzerhof, M. Generalized Gradient Approximation Made Simple. Phys Rev Lett 1996, 77 (18), 3865-3868. https://doi.org/10.1103/PhysRevLett.77.3865.

(64) Perdew, J. P.; Ruzsinszky, A.; Csonka, G. I.; Vydrov, O. A.; Scuseria, G. E.; Constantin, L. A.; Zhou, X.; Burke, K. Restoring the Density-Gradient Expansion for Exchange in Solids and Surfaces. Phys. Rev. Lett. 2008, $100 \quad$ (13), 136406. 
https://doi.org/10.1103/PhysRevLett.100.136406.

(65) Burdett, J. K.; Hughbanks, T.; Miller, G. J.; Richardson, J. W.; Smith, J. V. Structural-Electronic Relationships in Inorganic Solids: Powder Neutron Diffraction Studies of the Rutile and Anatase Polymorphs of Titanium Dioxide at 15 and 295 K. J. Am. Chem. Soc. 1987, 109 (12), 3639-3646. https://doi.org/10.1021/ja00246a021.

(66) Pascual, J.; Camassel, J.; Mathieu, H. Resolved Quadrupolar Transition in $\mathrm{TiO}_{2}$. Phys. Rev. Lett. 1977, 39 (23), 1490-1493. https://doi.org/10.1103/PhysRevLett.39.1490.

(67) DeFord, J. W.; Johnson, O. W. Electron Transport Properties in Rutile from 6 to 40 K. J. Appl. Phys. 1983, 54 (2), 889-897. https://doi.org/10.1063/1.332051.

(68) Frederikse, H. P. R. Recent Studies on Rutile $\left(\mathrm{TiO}_{2}\right)$. J. Appl. Phys. 1961, 32 (10), 2211-2215. https://doi.org/10.1063/1.1777045.

(69) Zhang, J.; Zhou, P.; Liu, J.; Yu, J. New Understanding of the Difference of Photocatalytic Activity among Anatase, Rutile and Brookite $\mathrm{TiO}_{2}$. Phys. Chem. Chem. Phys. 2014, 16 (38), 20382-20386. https://doi.org/10.1039/C4CP02201G.

(70) Péan, E.; Vidal, J.; Jobic, S.; Latouche, C. Presentation of the PyDEF PostTreatment Python Software to Compute Publishable Charts for Defect Energy Formation. Chem. Phys. Lett. 2017, 671, 124-130. https://doi.org/10.1016/j.cplett.2017.01.001.

(71) Stoliaroff, A.; Jobic, S.; Latouche, C. PyDEF 2.0: An Easy to Use Post-Treatment Software for Publishable Charts Featuring a Graphical User Interface. J. Comput. Chem. 2018, 39 (26), 2251-2261. https://doi.org/10.1002/jcc.25543.

(72) Pascual, J.; Camassel, J.; Mathieu, H. Fine Structure in the Intrinsic Absorption Edge of $\mathrm{TiO}_{2}$. Phys. Rev. B 1978, 18 (10), 5606-5614. https://doi.org/10.1103/PhysRevB.18.5606.

(73) Tezuka, Y.; Shin, S.; Ishii, T.; Ejima, T.; Suzuki, S.; Sato, S. Photoemission and Bremsstrahlung Isochromat Spectroscopy Studies of $\mathrm{TiO}_{2}$ (Rutile) and $\mathrm{SrTiO}_{3}$. J. Phys. Soc. Jpn. 1994, 63 (1), 347-357. https://doi.org/10.1143/JPSJ.63.347.

(74) Nowotny, M. K.; Bak, T.; Nowotny, J. Electrical Properties and Defect Chemistry of $\mathrm{TiO}_{2}$ Single Crystal. I. Electrical Conductivity. J. Phys. Chem. B 2006, 110 (33), 16270-16282. https://doi.org/10.1021/jp0606210.

(75) Aono, M.; Hasiguti, R. R. Interaction and Ordering of Lattice Defects in OxygenDeficient Rutile $\mathrm{TiO}_{2-\mathrm{x}}$ Phys. Rev. B 1993, 48 (17), 12406-12414. https://doi.org/10.1103/PhysRevB.48.12406.

(76) Eagles, D. M. Polar Modes of Lattice Vibration and Polaron Coupling Constants in Rutile $\left(\mathrm{TiO}_{2}\right)$. J. Phys. Chem. Solids 1964, 25 (11), 1243-1251. https://doi.org/10.1016/00223697(64)90022-8.

(77) Stoneham, A. M.; Gavartin, J.; Shluger, A. L.; Kimmel, A. V.; Ramo, D. M.; Rønnow, H. M.; Aeppli, G.; Renner, C. Trapping, Self-Trapping and the Polaron Family. J. Phys. Condens. Matter 2007, 19 (25), 255208. https://doi.org/10.1088/0953-8984/19/25/255208. 
(78) Finazzi, E.; Di Valentin, C.; Pacchioni, G. Nature of Ti Interstitials in Reduced Bulk Anatase and Rutile $\mathrm{TiO}_{2} . \quad J . \quad$ Phys. Chem. $C$ 2009, 113 (9), 3382-3385. https://doi.org/10.1021/jp8111793.

(79) Janotti, A.; Franchini, C.; Varley, J. B.; Kresse, G.; Walle, C. G. V. de. Dual Behavior of Excess Electrons in Rutile $\mathrm{TiO}_{2}$. Phys. Status Solidi RRL - Rapid Res. Lett. 2013, 7 (3), 199-203. https://doi.org/10.1002/pssr.201206464.

(80) Duckworth, C. N.; Brinkman, A. W.; Woods, J. Deep Level Transient Spectroscopy in $\mathrm{TiO}_{2}$ :Nb. Phys. Status Solidi $A$ 1983, 75 (1), K99-K102. https://doi.org/10.1002/pssa.2210750163.

(81) Das, S. The Al-O-Ti (Aluminum-Oxygen-Titanium) System. J. Phase Equilibria 2002, 23 (6), 525-536. https://doi.org/10.1361/105497102770331271.

(82) Cox, J. D.; Wagman, D. D.; Medvedev, V. A. CODATA Key Values for Thermodynamics. Hemisphere Publ. Corp 1984, 1.

(83) Kim, K. J.; Ran Park, Y.; Han Lee, J.; Choi, S.-L.; Jung Lee, H.; Sung Kim, C.; Yun Park, J. Room-Temperature Ferromagnetic Properties in Mn-Doped Rutile $\mathrm{TiO}_{2}-\delta$ Thin Films. $J$. Magn. Magn. Mater. 2007, 316 (2), e215-e218. https://doi.org/10.1016/j.jmmm.2007.02.093.

(84) Güler, S.; Rameev, B.; Khaibullin, R. I.; Lopatin, O. N.; Aktaş, B. EPR Study of Mn-Implanted Single Crystal $\mathrm{TiO}_{2} . \quad$ J. Phys. Conf. Ser. 2009, 153, 012052. https://doi.org/10.1088/1742-6596/153/1/012052.

(85) Xia, X. H.; Lu, L.; Walton, A. S.; Ward, M.; Han, X. P.; Brydson, R.; Luo, J. K.; Shao, G. Origin of Significant Visible-Light Absorption Properties of Mn-Doped $\mathrm{TiO}_{2}$ Thin Films. Acta Mater. 2012, 60 (5), 1974-1985. https://doi.org/10.1016/j.actamat.2012.01.006.

(86) Carter, D. L.; Okaya, A. Electron Paramagnetic Resonance of $\mathrm{Fe}^{3+}$ in $\mathrm{TiO}_{2}$ (Rutile). Phys. Rev. 1960, 118 (6), 1485-1490. https://doi.org/10.1103/PhysRev.118.1485.

(87) Kim, Y. J.; Thevuthasan, S.; Droubay, T.; Lea, A. S.; Wang, C. M.; Shutthanandan, V.; Chambers, S. A.; Sears, R. P.; Taylor, B.; Sinkovic, B. Growth and Properties of Molecular Beam Epitaxially Grown Ferromagnetic Fe-Doped $\mathrm{TiO}_{2}$ Rutile Films on $\mathrm{TiO}_{2}$ (110). Appl. Phys. Lett. 2004, 84 (18), 3531-3533. https://doi.org/10.1063/1.1703845.

(88) He, H.; Sun, D.; Zhang, Q.; Fu, F.; Tang, Y.; Guo, J.; Shao, M.; Wang, H. IronDoped Cauliflower-Like Rutile $\mathrm{TiO}_{2}$ with Superior Sodium Storage Properties. ACS Appl. Mater. Interfaces 2017, 9 (7), 6093-6103. https://doi.org/10.1021/acsami.6b15516.

(89) Xia, X. H.; Gao, Y.; Wang, Z.; Jia, Z. J. Structure and Photocatalytic Properties of Copper-Doped Rutile $\mathrm{TiO}_{2}$ Prepared by a Low-Temperature Process. J. Phys. Chem. Solids 2008, 69 (11), 2888-2893. https://doi.org/10.1016/j.jpcs.2008.07.011.

(90) Tryba, B.; Orlikowski, J.; Wróbel, R. J.; Przepiórski, J.; Morawski, A. W. Preparation and Characterization of Rutile-Type $\mathrm{TiO}_{2}$ Doped with Cu. J. Mater. Eng. Perform. 2015, 24 (3), 1243-1252. https://doi.org/10.1007/s11665-015-1405-5.

(91) Mudarra Navarro, A. M.; Bilovol, V.; Cabrera, A. F.; Rodríguez Torres, C. E.; 
Sánchez, F. H. The Relationship between Magnetic Behaviour and Local Structure around Fe Ions in Fe-Doped $\mathrm{TiO}_{2}$ Rutile. Phys. $B$ Condens. Matter 2009, 404 (18), 2838-2840. https://doi.org/10.1016/j.physb.2009.06.098.

(92) Yang, J. H.; Kitchaev, D. A.; Ceder, G. Rationalizing Accurate Structure Prediction in the Meta-GGA SCAN Functional. Phys. Rev. B 2019, 100 (3), 035132. https://doi.org/10.1103/PhysRevB.100.035132.

(93) Yang, Z.; Peng, H.; Sun, J.; Perdew, J. P. More Realistic Band Gaps from MetaGeneralized Gradient Approximations: Only in a Generalized Kohn-Sham Scheme. Phys. Rev. B 2016, 93 (20), 205205. https://doi.org/10.1103/PhysRevB.93.205205.

(94) Sun, J.; Remsing, R. C.; Zhang, Y.; Sun, Z.; Ruzsinszky, A.; Peng, H.; Yang, Z.; Paul, A.; Waghmare, U.; Wu, X.; Klein, M. L.; Perdew, J. P. Accurate First-Principles Structures and Energies of Diversely Bonded Systems from an Efficient Density Functional. Nat. Chem. 2016, 8 (9), 831-836. https://doi.org/10.1038/nchem. 2535.

(95) Momma, K.; Izumi, F. VESTA 3 for Three-Dimensional Visualization of Crystal, Volumetric and Morphology Data. J. Appl. Crystallogr. 2011, 44 (6), 1272-1276. https://doi.org/10.1107/S0021889811038970. 
For Table of Contents Use Only.

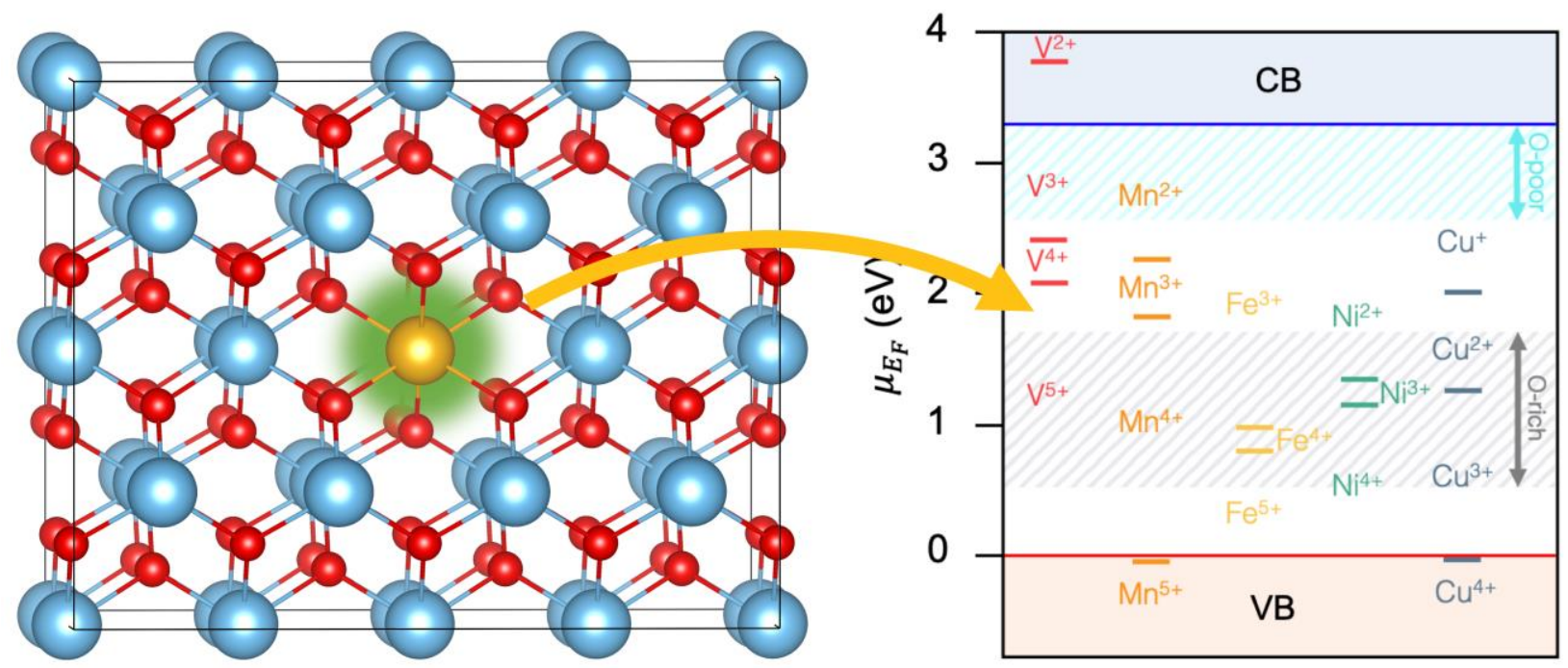

